WSRC-TR-99-00126

\title{
Determining Original Inventory Amount of Radioactive Substances from Unmonitored Radionuclide Emissions
}

by

J. T. Hamilton

Westinghouse Savannah River Company

Savannah River Site

Aiken, South Carolina 29808

B. C. Blunt

DOE Contract No. DE-AC09-96SR18500

This paper was prepared in connection with work done under the above contract number with the U.S.

Department of Energy. By acceptance of this paper, the publisher and/or recipient acknowledges the U.S. Government's right to retain a nonexclusive, royalty-free license in and to any copyright covering this paper, along with the right to reproduce and to authorize others to reproduce all or part of the copyrighted paper. 


\section{DISCLAIMER}

This report was prepared as an account of work sponsored by an agency of the United States Government. Neither the United States Government nor any agency thereof, nor any of their employees, makes any warranty, express or implied, or assumes any legal liability or responsibility for the accuracy, completeness, or usefulness of any information, apparatus, product, or process disclosed, or represents that its use would not infringe privately owned rights. Reference herein to any specific commercial product, process, or service by trade name, trademark, manufacturer, or otherwise does not necessarily constitute or imply its endorsement, recommendation, or favoring by the United States Government or any agency thereof. The views and opinions of authors expressed herein do not necessarily state or reflect those of the United States Government or any agency thereof.

This report has been reproduced directly from the best available copy.

Available to DOE and DOE contractors from the Office of Scientific and Technical Information, P.O. Box 62, Oak Ridge, TN 37831; prices available from (615) 576-8401.

Available to the public from the National Technical Information Service, U.S. Department of Commerce, 5285 Port Royal Road, Springfield, VA 22161. 


\section{DISCLAIMER}

Portions of this document may be illegible in electronic image products. Images are produced from the best available original document: 
WSRC-TR-99-00126

Revision 0

Determining Original Inventory Amount of Radioactive Substances from Unmonitored Radionuclide Emissions (U)

James T. Hamilton

Brent C. Blunt

Westinghouse Savannah River Company

Savannah River Site

Aiken, SC 29808 
(This page intentionally left blank) 


\section{Determining Original Inventory Amount of Radioactive Substances from Unmonitored Radionuclide Emissions (U)}

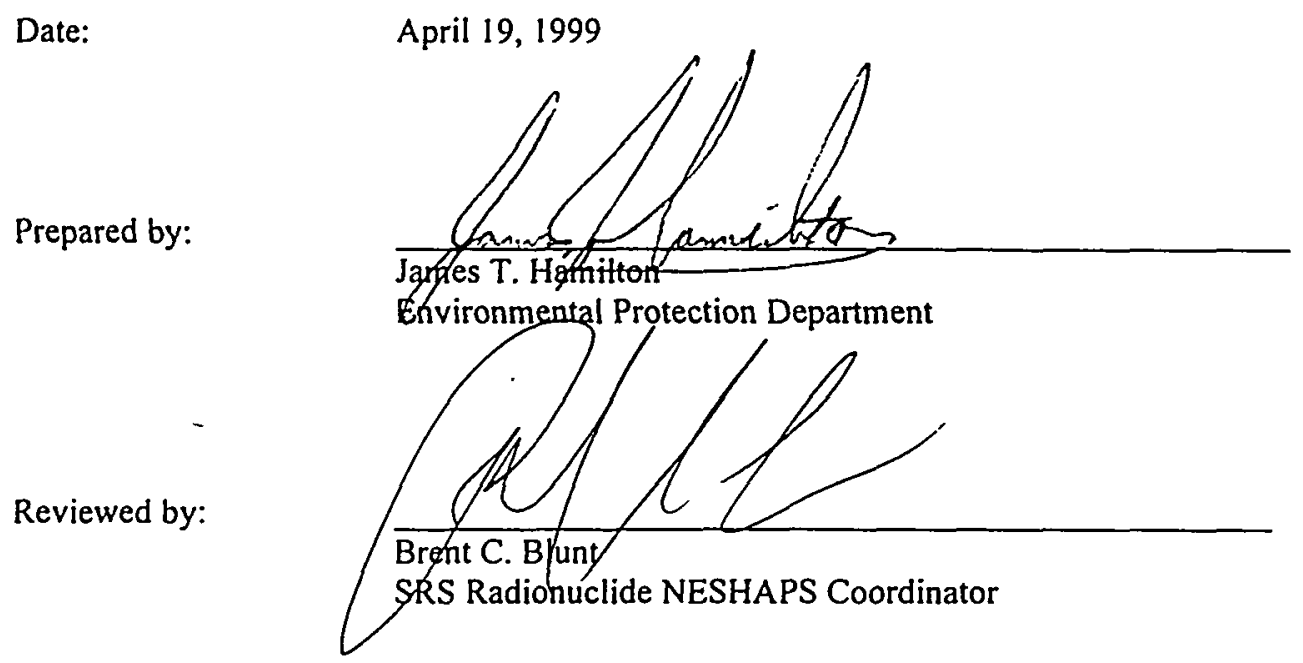

Westinghouse Savannah River Company

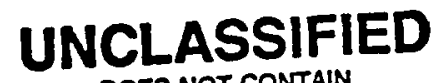
DOES NOT CONTANN UNGUASSIFIED CONTROLLEO

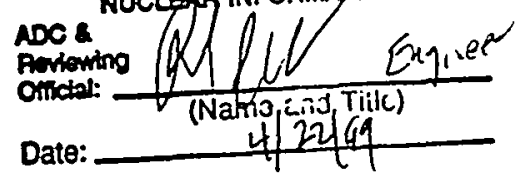


(This page intentionally left blank) 
WSRC-TR-99-00126

Determining Original Inventory Amount of Radioactive Substances

April 19, 1999

Revision 0

from Unmonitored Radionuclide Emissions (U)

Page 1 of 4

James T. Hamilton \& Brent C. Blunt

\subsection{Purpose and Scope}

This document is to accompany Determining Radionuclide Emissions from Unmonitored Sources (WSRC-TR-95-0378) for determination of the Air Emissions Inventory of the Savannah River Site. The calculation set forth in this document supercedes the original "BackCalculation of Inventory of Determining Radionuclide Emissions" located in section 5.1.6 of WSRC-TR-95-0378. In the previous calculation there exists a possibility of the denominator becoming zero when the release fraction value is equal to one. To satisfy regulatory requirements a new equation has been developed to determine original inventory amounts from unmonitored radionuclide emissions. The new equation is applicable to point sources, non-point sources, and inactive sources. This document contains a methodology section that explains the equation's derivation. Located in the appendices are two type written examples and four spreadsheet examples. Some redundancy in description of variables and definitions will occur between this document and its predecessor Determining Radionuclide Emissions from Unmonitored Sources (WSRCTR-95-0378).

\subsection{Definitions}

Radioactivity- The spontaneous emission of radiation, generally alpha or beta particles, often accompanied by gamma rays, from the nucleus of an unstable isotope. Also, the rate at which radioactive material emits radiation. Measured in units of becquerels or disintegrations per second (Reference 6.1).

Becquerels $(\mathrm{Bq})$ - The unit of radioactive decay, equal to one disintegration per second. Thirtyseven billion $\left(3.7 \times 10^{10}\right)$ becquerels is equal to one curie (Ci) (Reference 6.1).

Curie- The basic unit used to describe the intensity of radioactivity in a sample of material. The curie is equal to thirty-seven billion $\left(3.7 \times 10^{10}\right)$ disintegrations per second, which is approximately the activity of one gram of radium. A curie is also a quantity of any radionuclide that decays at a rate of thirty-seven billion disintegrations per second. It is named for
Marie and Pierre Curie, who discovered radium in 1898 (Reference 6.1).

Radionuclide- An unstable isotope of an element that decays or disintegrates spontaneously, emitting radiation. Approximately 5,000 natural and artificial radioisotopes have been identified (Reference 6.1).

Half-life- The time in which one half of the atoms of a particular radioactive substance disintegrates into another nuclear form. Measured half-lives vary from millionths of a second to billions of years. Also, called physical or radiological half-life. (Reference 6.1).

Point Source- A point source is an emission source with a well-defined single exhaust point, such as a stack or vent (Reference 6.2).

Non-point sources - Sources without well defined, single exhaust points. (Reference 6.2).

Inactive source- An inactive source is a source in which the process design function is no longer being utilized. An inactive source is in a shutdown mode, typically awaiting decontamination and decommissioning. An inactive source does not lend itself to evaluation by traditional stack sampling and monitoring techniques (Reference 6.2).

\subsection{Guides}

\subsection{Modified NUREG 1400 Method}

NUREG 1400 provides examples, methods, and techniques for air sampling that may be useful for implementing the recommendations in Regulatory Guide 8.25, "Air Sampling in the Workplace," and the requirements of $10 \mathrm{CFR}$ Part 20 (Reference 6.3).

NUREG 1400 sets forth guidelines for determining the need for air sampling in the workplace. Workplace air sampling is used to calculate potential worker intake, the control equipment that is necessary to control intake amounts, and warn of elevated levels of airborne radioactive substances. Calculations in NUREG 1400 allow for the determination of airborne radioactive emissions from unmonitored sources. NUREG 1400 has become a vital part in accomplishing the Air Emissions Inventory for 
WSRC-TR-99-00126

April 19, 1999

Revision 0

Determining Original Inventory Amount of Radioactive Substances

Page 2 of 4

from Unmonitored Radionuclide Emissions (U)

James T. Hamilton \& Brent C. Blunt

Title $\mathrm{V}$ of the Clean Air Act. The Savannah

River Site has emission points, which do not meet the requirements for continuous air sample monitoring. These emission points are sampled at least once on an annual, semiannual, or quarterly basis. Using the collected sample data and appropriate NUREG 1400 release fraction guidelines the emissions to the surrounding environment can be determined.

\subsection{Release Fraction (R)}

The release fraction (R) is the fraction of radioactive material likely to be released into the workplace breathing air, as determined by its physical and chemical form. The NRC has published suitable release fractions; adapted release fractions from 10 CFR 30.72 are presented in Table 3.2.1(Reference 6.3).

\begin{tabular}{|l|c|}
\hline \multicolumn{1}{|c|}{ Physical Form } & Release Fraction \\
\hline $\begin{array}{l}\text { Gases or } \\
\text { Volatile material }\end{array}$ & 1.0 \\
\hline Nonvolatile powders & 0.01 \\
\hline $\begin{array}{l}\text { Solids, (e.g., uranium } \\
\text { fuel pellets, cobalt, or } \\
\text { iridium metal) }\end{array}$ & 0.001 \\
\hline Liquids & 0.01 \\
\hline Encapsulated Material & 0.0 \\
\hline \multicolumn{2}{|c|}{ Table 3.2.1. Release Fractions } \\
\hline
\end{tabular}

The values shown in the table are used in the modified NUREG 1400 Method as release fraction values. If any nuclide is heated to a temperature of 100 degrees Celsius or more, boils at a temperature of 100 degrees Celsius or less, or is intentionally dispersed into the environment (interpreted as the atmosphere), it must be considered to be a gas (per 40 CFR 61 Appendix D 2(b)) (Reference 6.2).

At sources where the material is in a variety of physical forms (e.g., liquid, solid, gaseous) and the proportions are not known, the physical form providing the highest emissions estimate is assigned to all materials. Where the proportions are known, an appropriate ratio is used to derive the source term (Reference 6.4).

The release fraction(s) is used in the calculation of back inventory amount to account for the portion of the radioactive substance that has been released, disturbed, evaporated, and/or eroded from the original source location. The release fraction is an additive term to the radioactive decay portion of the radioactive emissions as shown in the derivation located in section 4.0.

Note the use of release fractions $(0 \& 1)$ in spreadsheet format causes the propagation of what seems to be strange numbers for back inventory amounts. With some logical interpretation the "strange" numbers have significant meaning. Should " 0 " be used for a release fraction the air release term becomes null and is no longer part of the calculation. So over the period of time in question the radioactive decay has been determined. Should " 1 " be used for a release fraction it should be apparent that all of a gas or volatile material will be released to the surrounding environment on the first day.

\subsection{Methodology}

Variables:

\begin{tabular}{|c|c|c|}
\hline A & $=$ & Activity $(\mathrm{Ci})$ amount at time of sample $(t+0)$ \\
\hline$A_{0}$ & $=$ & Activity $(\mathrm{Ci})$ at time zero $(\mathrm{t}=0)$ \\
\hline$t$ & $=$ & $\begin{array}{l}\text { Time in days (from beginning of reference period to end of reference } \\
\text { period when sample is taken) }\end{array}$ \\
\hline$\lambda$ & $=$ & Radioactive decay constant in (days ${ }^{-1}$ ) \\
\hline $\mathrm{R}$ & $=$ & $\begin{array}{l}\text { Release fraction for applicable physical forms of radioactive } \\
\text { substances: (See Table 3.2.1) }\end{array}$ \\
\hline$A_{\text {release }}$ & $=$ & Air emission portion of radioactive substance \\
\hline $\mathrm{D}_{\text {release }}$ & $=$ & Decay emission portion of radioactive substance \\
\hline B & $=$ & Total released ( $T_{\text {release }}$ ) due to $A_{\text {release }}$ and $D_{\text {release }}$ calculated in (Ci) \\
\hline $\mathrm{B}_{0}$ & $=$ & Back inventory amount $(\mathrm{Ci})$ \\
\hline
\end{tabular}


WSRC-TR-99-00126

Determining Original Inventory Amount of Radioactive Substances

April 19, 1999

Revision 0

from Unmonitored Radionuclide Emissions (U)

Page 3 of 4

James T. Hamilton \& Brent C. Blunt

Basic Equations:

$$
\begin{aligned}
& A=A_{0}{ }^{*} e^{-\lambda t} \quad\left(D_{\text {release }}\right) \\
& A_{\text {release }}=A_{0}{ }^{*} R
\end{aligned}
$$

Known Values:

$$
A, t, R, \lambda
$$

\section{Assumptions and/or Statement of Facts:}

1. Activity measurement at time " $t$ " $(A)$ is a value that takes into account the radioactive decay $\left(A=A_{0}{ }^{*} e^{-\lambda t}\right)$ at that particular point in time.

2. It is assumed the samples and calculations take place at the end of the day.

Derivation:

$$
\begin{array}{cc}
\left(A=A_{o}^{*} e^{-\lambda t}\right) & \left(A_{o}=A^{*} e^{\lambda t}\right) \\
\text { decay } & \text { growth }
\end{array}
$$

$$
\begin{aligned}
& T_{\text {release }}=A_{\text {release }}+D_{\text {release }} \\
& A_{\text {release: }} \quad A_{0}{ }^{*} R \quad \text { equivalent to } \quad\left(A^{*} e^{\lambda l}\right) * R \\
& D_{\text {release: }} \quad A=A_{0}{ }^{*} e^{-\lambda t} \quad(A \text { is known at time " } t \text { ") } \\
& T_{\text {release }}=\left(A^{*} e^{\lambda t}\right) * R+A \\
& \left(B=B_{0}^{*} e^{-\lambda t}\right) \quad\left(B_{0}=B^{*} e^{\lambda t}\right) \\
& \text { decay growth }
\end{aligned}
$$

where: $\mathrm{B}=\mathrm{T}_{\text {release }}$

$$
\begin{aligned}
& B_{0}=\left(T_{\text {release }}\right)^{*} e^{\lambda t} \\
& B_{0}=\left[\left(A^{*} e^{\lambda t}\right)^{*} R+A\right]^{*} e^{\lambda t} \\
& B_{0}=\text { Original Inventory Amount in }(C i)
\end{aligned}
$$


WSRC-TR-99-00126

Determining Original Inventory Amount of Radioactive Substances

from Unmonitored Radionuclide Emissions (U)

James T. Hamilton \& Brent $C$. Blunt
April 19, 1999

Revision 0

Page 4 of 4

\subsection{Discussion of Methodology}

The basic equation for the premise of the calculation is the first order growth and decay model. Assumption and/or statement of fact number one allows for the derivation of the calculation for back inventory. It is the realization that at the instantaneous point in time when the activity of the radioactive emission is sampled the activity is a measurement of the radioactive decay $\left(A=A_{0}{ }^{*} e^{-\lambda t}\right)$ where " $A$ " is the activity reading. Time " $t$ " will need to be established from some reference datum, perhaps from when emissions began or from when the last sample was pulled, (e.g. yearly for the Air Emissions Inventory). Assumption and/or statement of fact number two is necessary to avoid the problem of fractional components of time (whole units of time are preferred but not absolutely necessary).

Located in Appendix A is the spreadsheet calculation for back inventory amounts. This spreadsheet calculation along with the accompanying graph enabled the derivation of the equation for calculating back inventories. The circular calculation assumes an original inventory amount $\left(\mathrm{B}_{0}\right)$ and works backward to find the necessary steps that must take place in order to determine the inventory amount; given only the current amount (A). The graph shows one exponential growth curve (pink) and two exponential decay curves (blue \& yellow). The pink curve is the amount of radioactive substance(s) that has decayed and been released due to the air release fraction. The blue and yellow curves indicate the amount of radioactive substance(s) left after decay and the air release fraction. The yellow exponential decay curve is the graph of the formula derived in section 4.0 "Methodology". The blue and pink curves are graphs of the circular calculation formulas in Appendix A. Interpretation of the graph indicates the newly derived formula (Formula $B$ ) is representative of the circular calculation for determining back inventory amounts. Also, within Appendix A there are three additional spreadsheet examples of the new back inventory calculation. Each example shows the calculation being preformed with a different air release fraction.
Appendix B offers two typewritten examples with applications of the new back inventory calculation.

\subsection{References}

6.1 Nuclear Regulatory Commission. "Glossary of Nuclear Terms." http://www.nrc.gov/NRC/ EDUCATE/GLOSSARY/index.html, (March 31,1999).

6.2 Martha C. Thompson. Determining Radionuclide Emissions from Unmonitored Sources. WSRC-TR-95-0378, Revision 1, Westinghouse Savannah River Company, Aiken, SC 29808 (July 1999).

6.3 E.E. Hickey, G.A. Stoetzel, et, al. Air Sampling in the Workplace. NUREG 1400, USNRC, Washington, DC (September 1993).

6.4 Savannah River Site Unmonitored Source Evaluations and Schedule for Confirmatory Measurements. ESH-ESG-910667, Westinghouse Savannah River Company, Aiken, SC 29808 (December 1991). 
APPENDIX A 
(This page intentionally left blank) 


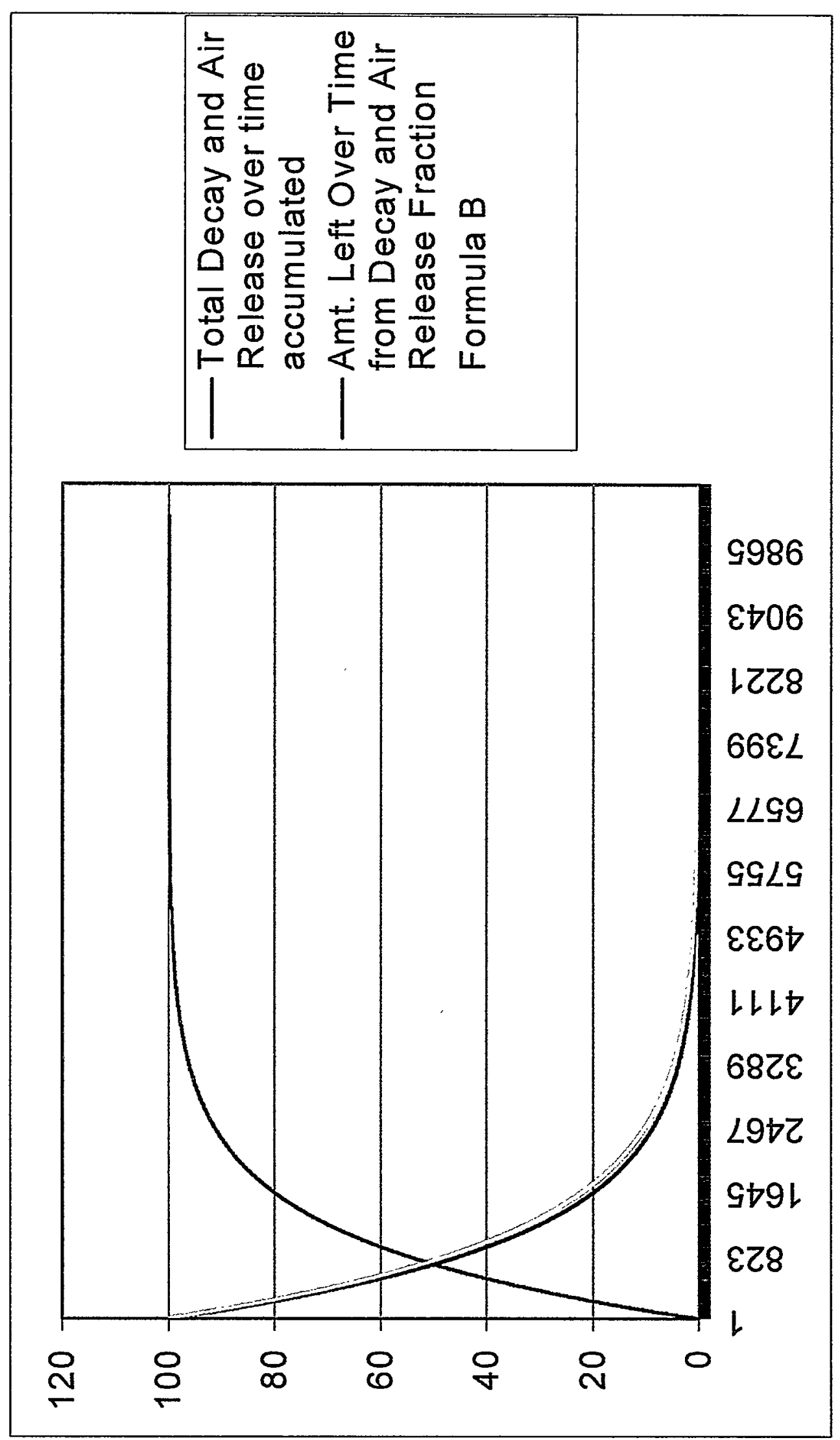


(This page intentionally left blank) 


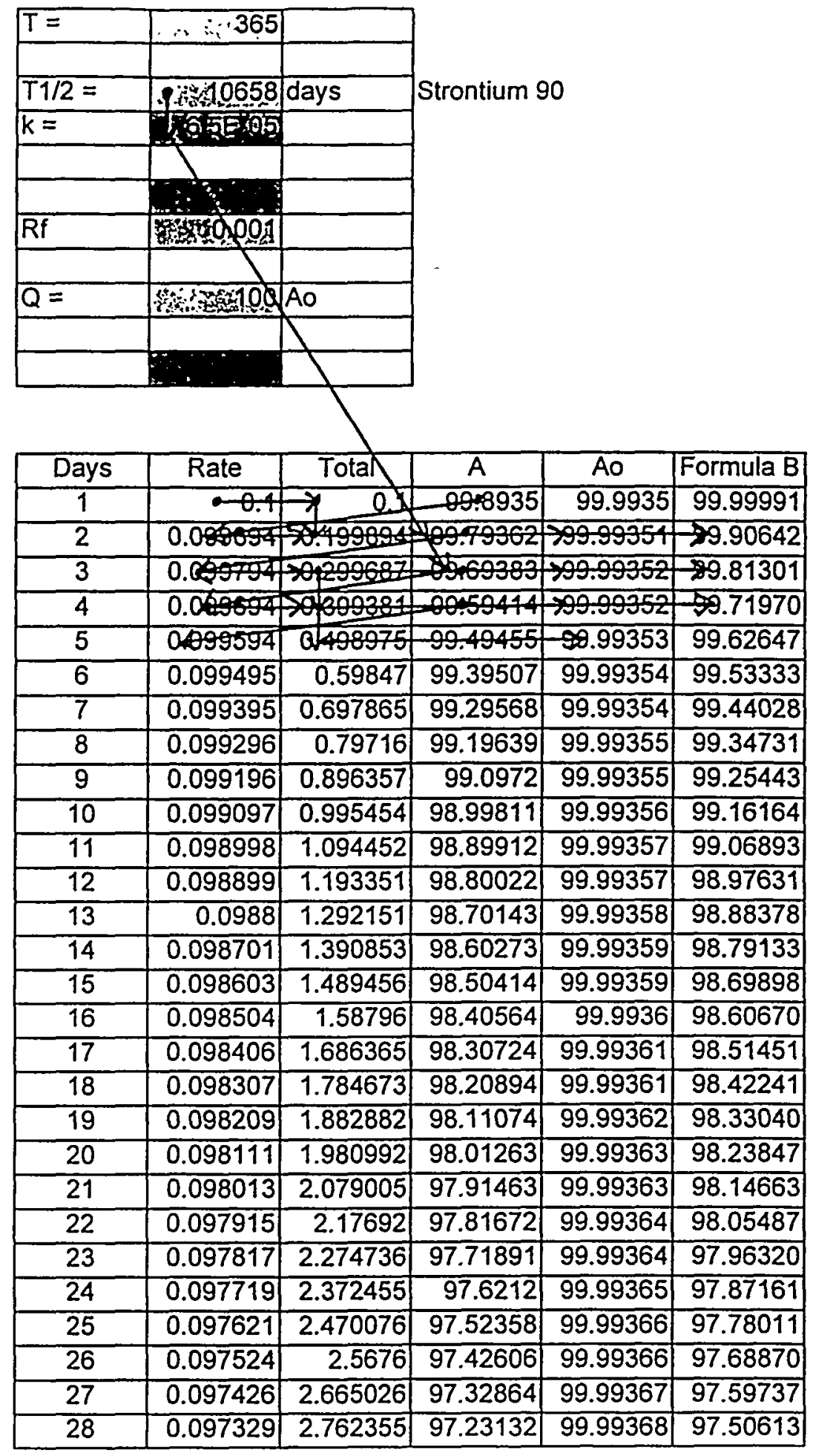




\begin{tabular}{|c|c|c|c|c|c|}
\hline 10617 & $2.44 E-06$ & 99.99756 & 0.002438 & 100 & 0.00487 \\
\hline 10618 & $2.44 E-06$ & 99.99756 & 0.002436 & 100 & 0.00487 \\
\hline 10619 & $2.44 E-06$ & 99.99757 & 0.002433 & 100 & 0.00486 \\
\hline 10620 & $2.43 E-06$ & 99.99757 & 0.002431 & 100 & 0.00486 \\
\hline 10621 & $2.43 E-06$ & 99.99757 & 0.002428 & 100 & 0.00485 \\
\hline 10622 & $2.43 E-06$ & 99.99757 & 0.002426 & 100 & 0.00485 \\
\hline 10623 & $2.43 E-06$ & 99.99758 & 0.002424 & 100 & 0.00485 \\
\hline 10624 & $2.42 \mathrm{E}-06$ & 99.99758 & 0.002421 & 100 & 0.00484 \\
\hline 10625 & $2.42 E-06$ & 99.99758 & 0.002419 & 100 & 0.00484 \\
\hline 10626 & $2.42 \mathrm{E}-06$ & 99.99758 & 0.002416 & 100 & 0.00483 \\
\hline 10627 & $2.42 E-06$ & 99.99759 & 0.002414 & 100 & 0.00483 \\
\hline 10628 & $2.41 \mathrm{E}-06$ & 99.99759 & 0.002411 & 100 & 0.00482 \\
\hline 10629 & $2.41 E-06$ & 99.99759 & 0.002409 & 100 & 0.00482 \\
\hline 10630 & $2.41 E-06$ & 99.99759 & 0.002407 & 100 & 0.00481 \\
\hline 10631 & $2.41 \mathrm{E}-06$ & 99.9976 & 0.002404 & 100 & 0.00481 \\
\hline 10632 & $2.4 \mathrm{E}-06$ & 99.9976 & 0.002402 & 100 & 0.00481 \\
\hline 10633 & $2.4 \mathrm{E}-06$ & 99.9976 & 0.002399 & 100 & 0.00480 \\
\hline 10634 & $2.4 \mathrm{E}-06$ & 99.9976 & 0.002397 & 100 & 0.00480 \\
\hline 10635 & $2.4 E-06$ & 99.99761 & 0.002395 & 100 & 0.00479 \\
\hline 10636 & $2.39 E-06$ & 99.99761 & 0.002392 & 100 & 0.00479 \\
\hline 10637 & $2.39 E-06$ & 99.99761 & 0.00239 & 100 & 0.00478 \\
\hline 10638 & $2.39 E-06$ & 99.99761 & 0.002387 & 100 & 0.00478 \\
\hline 10639 & $2.39 E-06$ & 99.99761 & 0.002385 & 100 & 0.00477 \\
\hline 10640 & $2.39 E-06$ & 99.99762 & 0.002383 & 100 & 0.00477 \\
\hline 10641 & $2.38 \mathrm{E}-06$ & 99.99762 & 0.00238 & 100 & 0.00476 \\
\hline 10642 & $2.38 \mathrm{E}-06$ & 99.99762 & 0.002378 & 100 & 0.00476 \\
\hline 10643 & $2.38 E-06$ & 99.99762 & 0.002376 & 100 & 0.00476 \\
\hline 10644 & $2.38 \mathrm{E}-06$ & 99.99763 & 0.002373 & 100 & 0.00475 \\
\hline 10645 & $2.37 E-06$ & 99.99763 & 0.002371 & 100 & 0.00475 \\
\hline 10646 & 2.37E-06 & 99.99763 & 0.002368 & 100 & 0.00474 \\
\hline 10647 & $2.37 E-06$ & 99.99763 & 0.002366 & 100 & 0.00474 \\
\hline 10648 & $2.37 E-06$ & 99.99764 & 0.002364 & 100 & 0.00473 \\
\hline 10649 & $2.36 \mathrm{E}-06$ & 99.99764 & 0.002361 & 100 & 0.00473 \\
\hline 10650 & $2.36 \mathrm{E}-06$ & 99.99764 & 0.002359 & 100 & 0.00472 \\
\hline 10651 & $2.36 E-06$ & 99.99764 & 0.002357 & 100 & 0.00472 \\
\hline 10652 & $2.36 \mathrm{E}-06$ & 99.99765 & 0.002354 & 100 & 0.00472 \\
\hline 10653 & $2.35 E-06$ & 99.99765 & 0.002352 & 100 & 0.00471 \\
\hline 10654 & $2.35 E-06$ & 99.99765 & 0.00235 & 100 & 0.00471 \\
\hline 10655 & $2.35 \mathrm{E}-06$ & 99.99765 & 0.002347 & 100 & 0.00470 \\
\hline 10656 & $2.35 E-06$ & 99.99765 & 0.002345 & 100 & 0.00470 \\
\hline 10657 & $2.34 E-06$ & 99.99766 & 0.002343 & 100 & 0.00469 \\
\hline 10658 & $2.34 \mathrm{E}-06$ & 99.99766 & 0.00234 & 100 & 0.00469 \\
\hline
\end{tabular}




\begin{tabular}{|c|c|c|c|c|c|c|c|c|}
\hline$=$ & $\begin{array}{r}10658 \\
\therefore\end{array}$ & 10658 & $\begin{array}{l}T 1 / 2 \\
=\end{array}$ & 52 & 52 & $\begin{array}{l}T 1 / 2 \\
=\end{array}$ & 13 & 13 \\
\hline $\mathrm{k}=$ & $6504 \mathrm{E} 05$ & $61504 \mathrm{E}^{2} \mathrm{~s}$ & $k=$ & 2000133298 & $0 \geq 0133298$ & $\mathrm{k}=$ & 201053379 & 03053349 \\
\hline & & & & & & & & \\
\hline$R f$ & $\because \div 0.01$ & 0.001 & $\mathrm{Rf}$ & 0.01 & 0.001 & $\mathrm{Rf}$ & 0 & it \\
\hline & & & & & & & & \\
\hline$A O=$ & 100 & 100 & $A O=$ & 100 & 100 & $\widehat{A O}=$ & 100 & 100 \\
\hline$A=$ & $\therefore 50$ & 50 & $A=$ & 50 & 50 & $A=$ & 50 & 50 \\
\hline & Strontium & 90 & \multicolumn{3}{|c|}{ Strontium } & \multicolumn{2}{|r|}{ Cesium } & 136 \\
\hline Days & Formula B & Formula B & Days & Formula B & Formula B & Days & Formula B & $\begin{array}{l}\text { Formula } \\
\mathrm{B}\end{array}$ \\
\hline 1 & 50.50332 & 50.05326 & 1 & 51.18446 & 50.72230 & $\overline{1}$ & 52.73830 & 108.3648 \\
\hline 2 & 50.50663 & 50.05652 & 2 & 51.87829 & 51.40364 & 2 & 55.62657 & 117.5128 \\
\hline 3 & 50.50995 & 50.05978 & 3 & 52.58161 & 52.09414 & 3 & 58.67302 & 127.5235 \\
\hline 4 & 50.51327 & 50.06303 & 4 & 53.29457 & 52.79393 & $\overline{4}$ & 61.88631 & 138.4846 \\
\hline 5 & 50.51659 & 50.06629 & 5 & 54.01729 & 53.50313 & 5 & 65.27558 & 150.4936 \\
\hline 6 & 50.51990 & 50.06955 & 6 & 54.74992 & 54.22186 & 6 & 68.85047 & 163.6582: \\
\hline 7 & 50.52322 & 50.07281 & 7 & 55.49259 & 54.95026 & 7 & 72.62114 & 178.0977: \\
\hline 8 & 50.52654 & 50.07607 & 8 & 56.24544 & 55.68846 & 8 & 76.59832 & 193.9443 \\
\hline 9 & 50.52986 & 50.07933 & 9 & 57.00861 & 56.43658 & 9 & 80.79331 & 211.3444 \\
\hline 10 & 50.53318 & 50.08259 & 10 & 57.78225 & 57.19477 & $\overline{10}$ & 85.21804 & 230.4603 \\
\hline 11 & 50.53650 & 50.08585 & 11 & 58.56651 & 57.96315 & 11 & 89.88510 & 251.4717 \\
\hline 12 & 50.53982 & 50.08911 & 12 & 59.36153 & 58.74187 & 12 & 94.80775 & 274.5779 \\
\hline 13 & 50.54314 & 50.09238 & 13 & 60.16746 & 59.53107 & $\overline{13}$ & 100.00000 & 300.0000 \\
\hline 14 & 50.54646 & 50.09564 & 14 & 60.98447 & 60.33087 & 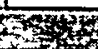 & 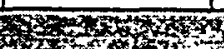 & 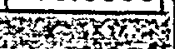 \\
\hline 15 & 50.54978 & 50.09890 & 15 & 61.81269 & 61.14144 & $x$ & 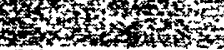 & 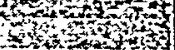 \\
\hline 16 & 50.55310 & 50.10216 & 16 & 62.65230 & 61.96291 & KEY: & & \\
\hline 17 & 50.55642 & 50.10542 & 17 & 63.50344 & 62.79543 & $=$ & Radic & ays) \\
\hline 18 & 50.55974 & 50.10868 & 18 & 64.36629 & 63.63916 & $\begin{array}{l}k \text { or } \\
\lambda=\end{array}$ & $\begin{array}{l}\text { Radioactive d } \\
\left(\text { days }^{-1}\right)\end{array}$ & onstant \\
\hline 19 & 50.56306 & 50.11195 & 19 & 65.24101 & 64.49423 & $\mathrm{Rf}=$ & Release fracti & \\
\hline 20 & 50.56638 & 50.11521 & 20 & 66.12777 & 65.36080 & $\overline{A O}=$ & Original Inven & Amt. (Ci) \\
\hline 21 & 50.56970 & 50.11847 & 21 & 67.02672 & 66.23904 & $A=$ & Amt. @ samp & $m e$ "t" (Ci) \\
\hline 22 & 50.57302 & 50.12173 & 22 & 67.93805 & 67.12909 & tis & 6 & $x+x_{0}$ \\
\hline 23 & 50.57634 & 50.12500 & 23 & 68.86194 & 68.03112 & & & 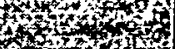 \\
\hline 24 & 50.57967 & 50.12826 & 24 & 69.79855 & 68.94528 & & & 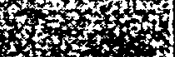 \\
\hline 25 & 50.58299 & 50.13152 & 25 & 70.74807 & 69.87175 & & & \% \\
\hline 26 & 50.58631 & 50.13479 & 26 & 71.71068 & 70.81068 & $y=3$ & & 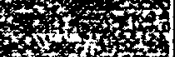 \\
\hline 27 & 50.58963 & 50.13805 & 27 & 72.68656 & 71.76225 & +4 & & $7 x^{2}$ \\
\hline 28 & 50.59296 & 50.14131 & 28 & 73.67591 & 72.72662 & & & 槹 \\
\hline 29 & 50.59628 & 50.14458 & 29 & 74.67891 & 73.70397 & ste & & \\
\hline 30 & 50.59960 & 50.14784 & 30 & 75.69576 & 74.69448 & 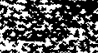 & $5 x$ & \\
\hline 31 & 50.60293 & 50.15111 & 31 & 76.72665 & 75.69832 & +8 & 4 & \\
\hline 32 & 50.60625 & 50.15437 & 32 & 77.77178 & 76.71566 & $3 x$ & W & then \\
\hline 33 & 50.60957 & 50.15764 & 33 & 78.83136 & 77.74671 & $3 x$ & 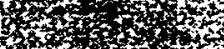 & \\
\hline 34 & 50.61290 & 50.16090 & 34 & 79.90558 & 78.79163 & Gion & - 73 & \\
\hline 35 & 50.61622 & 50.16417 & 35 & 80.99467 & 79.85062 & 1) & 6 & 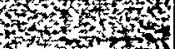 \\
\hline 36 & 50.61955 & 50.16744 & 36 & 82.09882 & 80.92386 & 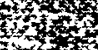 & 13 & 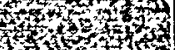 \\
\hline 37 & 50.62287 & 50.17070 & 37 & 83.21826 & 82.01155 & 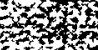 & 6 & \\
\hline 38 & 50.62620 & 50.17397 & 38 & 84.35319 & 83.11389 & 6 & Th & \\
\hline 39 & \begin{tabular}{|l|}
50.62952 \\
\end{tabular} & 50.17723 & 39 & 85.50386 & 84.23106 & 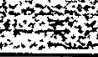 & 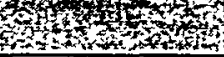 & \\
\hline
\end{tabular}




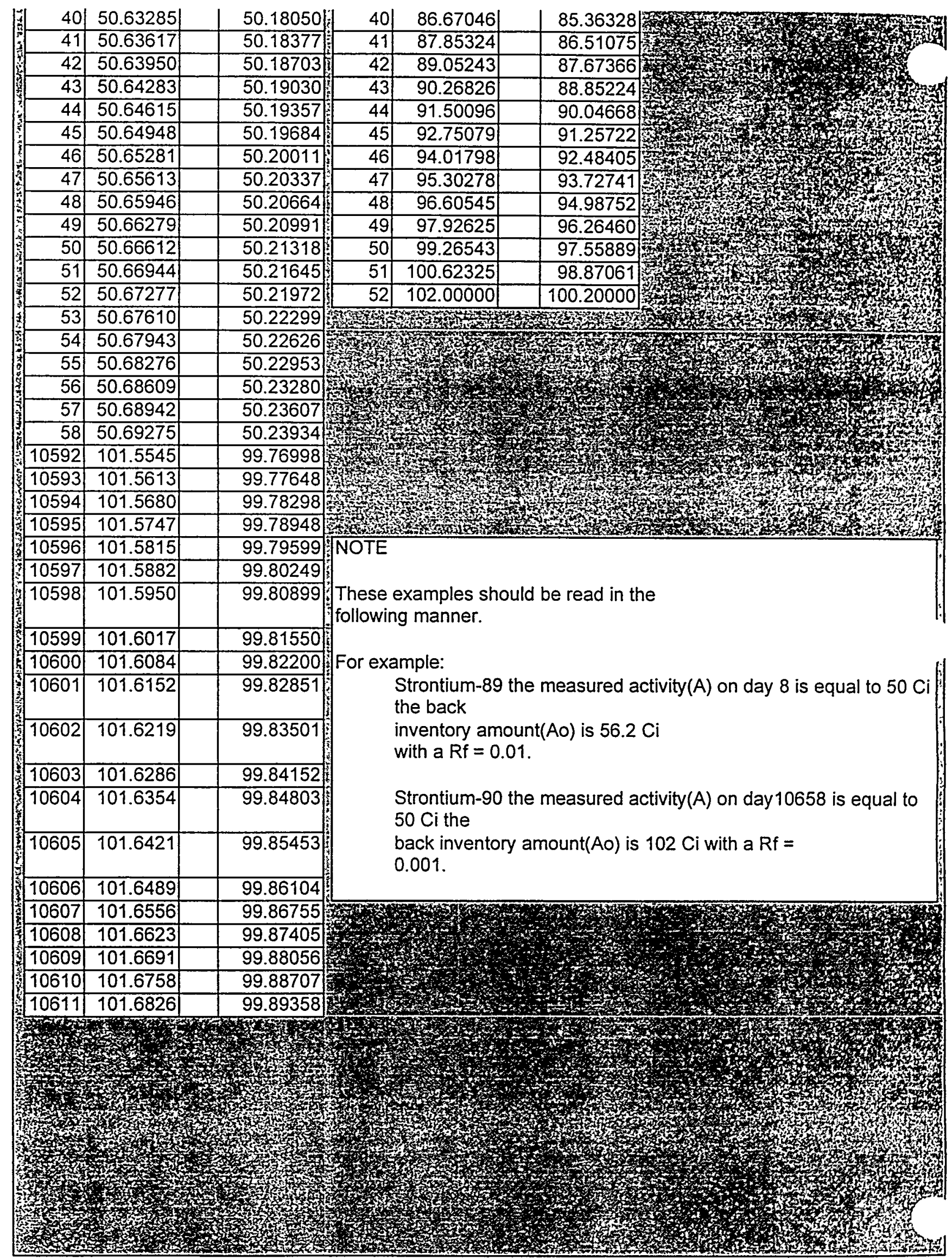




\begin{tabular}{|c|c|c|}
\hline 10614 & 101.7028 & 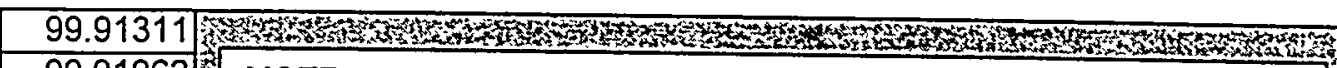 \\
\hline 10615 & 101.7095 & 99.91962 NO \\
\hline 10616 & 101.7163 & 99.92613 \\
\hline 10617 & 101.7230 & 99.932659 \\
\hline 10618 & 101.7298 & 99.93916 \\
\hline 10619 & 101.7365 & 99.94567 \\
\hline 10620 & 101.7433 & 99.95218 \\
\hline 10621 & 101.7500 & 99.95870 \\
\hline 10622 & 101.7568 & 99.96521 \\
\hline 10623 & 101.7635 & 99.97173 \\
\hline 10624 & 101.7703 & 99.97824 \\
\hline 10625 & 101.7770 & 99.98476 \\
\hline 10626 & 101.7838 & 99.99127 \\
\hline 10627 & 101.7905 & 99.99779 \\
\hline 10628 & 101.7973 & 100.00431 \\
\hline 10629 & 101.8040 & 100.01082 \\
\hline 10630 & 101.8108 & 100.01734 \\
\hline 10631 & 101.8175 & 100.02386 \\
\hline 10632 & 101.8243 & 100.03038 \\
\hline 10633 & 101.8310 & 100.03689 \\
\hline 10634 & 101.8378 & 100.04341 \\
\hline 10635 & 101.8445 & 100.04993 \\
\hline 10636 & 101.8513 & 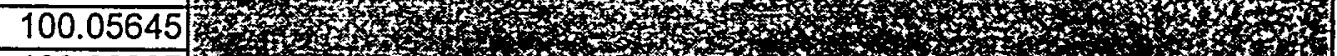 \\
\hline 10637 & 101.8580 & 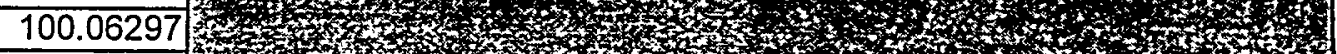 \\
\hline 10638 & 101.8648 & 100.069490 \\
\hline 10639 & 101.8715 & 100.07602 \\
\hline 10640 & 101.8783 & 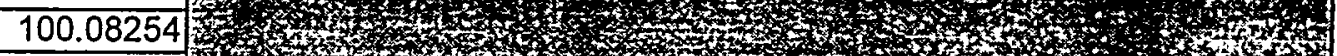 \\
\hline 10641 & 101.8850 & 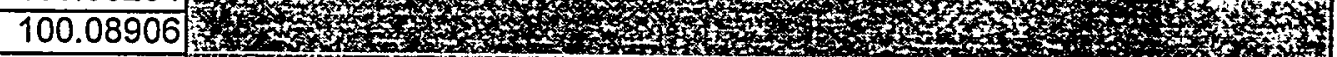 \\
\hline 10642 & 101.8918 & 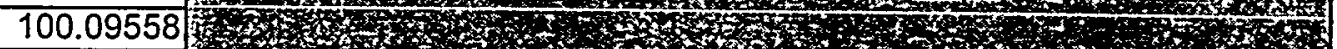 \\
\hline 10643 & 101.8986 & 100.10210 \\
\hline 10644 & 101.9053 & 100.10863 \\
\hline 10645 & 101.9121 & 100.11515 \\
\hline 10646 & 101.9188 & 100.12168 \\
\hline 10647 & 101.9256 & 100.12820 \\
\hline$\sqrt[2]{10648}$ & 101.9323 & 100.13473 \\
\hline 10649 & 101.9391 & 100.14125 \\
\hline 10650 & 101.9459 & 100.14778 \\
\hline 10651 & 101.9526 & 100.15430 \\
\hline 10652 & 101.9594 & $100.16083,-\gamma, z$ \\
\hline 10653 & 101.9661 & $100.16736<3$ \\
\hline 10654 & 101.9729 & 100.17389 \\
\hline 10655 & 101.9797 & $100.18041 / 3$ \\
\hline 10656 & 101.9864 & 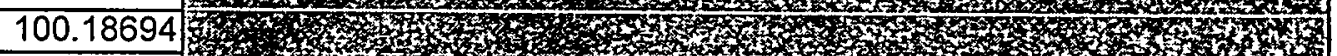 \\
\hline 10657 & 101.9932 & 100.19347 \\
\hline 10658 & 102.0000 & 100.20000 \\
\hline & 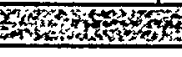 & \\
\hline
\end{tabular}


(This page intentionally left blank) 


\section{APPENDIX B}

\section{DISCLAIMER}

Examples provided in this appendix are solely for the purpose of leaming and performing the back inventory calculation. Any similarities to actual occurrences or processes that have occurred, occur, or will occur on the Savannah River Site are purely coincidental. The history and technical accuracy of the examples may not necessarily be correct, BUT it is the methodology the examples demonstrate that is important. 


\section{Example 1:}

A lab technician prepares a solution containing Pu-239 in an Erlenmeyer flask. The unstoppered flask is placed in an operating fume hood. What was the original inventory amount in the solution after 1 year? At time " $t$ " the activity was measured at 10 curies. Remember to use the appropriate air release fraction.

$$
\begin{array}{ll}
\text { Known Values: } & \mathrm{A} \\
\mathrm{T}_{1 / 2} & =10 \mathrm{Ci} \\
\mathrm{R} & =0.01 \text { (liquids) } \\
\mathrm{t} & =365 \text { days }
\end{array}
$$

STEP ONE: Determine radioactive decay constant.

$(\lambda$ or $k)=\frac{\ln 2}{8906000} \quad$ yields $\quad 7.78 \times 10^{-8}$ days $^{-1}$

STEP TWO: Determine the back inventory amount.

$$
\begin{aligned}
& \mathrm{B}_{0}=\left(\left(A e^{\lambda t}\right) R+A\right) e^{\lambda t} \\
& \mathrm{~B}_{0}=\left(\left(10 e^{7.78 \times 10^{-x} * 365}\right) 0.01+10\right) e^{7.78 \times 10^{-x} * 365} \\
& \mathrm{~B}_{0}=10.1 \mathrm{Ci}
\end{aligned}
$$

Should you wish to find the inventory amounts in grams $(\mathrm{g})$ use the specific activity of the radionuclide in question.

Example 1a: $\quad \mathrm{SpA}$ of $\mathrm{Pu}-239=6.13 \times 10^{-2}(\mathrm{Ci} / \mathrm{g})$

$$
\begin{array}{ll}
\text { Mass of Pu-239 in solution } & =\frac{10.1}{6.13 \times 10^{-2}} \\
\text { Mass of } \mathrm{Pu}-239 \text { in solution } & =164.763 \mathrm{~g}
\end{array}
$$




\section{Example 2:}

Strontium 90 is present in a fuel pellet. The fuel pellet is exposed to the surrounding environment for a period of 10 years. What is the original inventory amount of Strontium 90 in the fuel pellet? At time " $t$ " the activity was measured at 100 curies. Remember to use the appropriate air release fraction.

Known Values: $\mathrm{A} \quad=100 \mathrm{Ci}$

$$
\begin{array}{ll}
T_{1 / 2} & =28.1 \text { years or } 10658 \text { days } \\
\mathrm{R} & =0.001 \text { (solids) } \\
\mathrm{t} & =3650 \text { days }
\end{array}
$$

STEP ONE: Determine radioactive decay constant.

$(\lambda$ or $k)=\frac{\ln 2}{10658} \quad$ yields $\quad 6.504 \times 10^{-5}$ days $^{-1}$

STEP TWO: Determine the back inventory amount.

$\mathrm{B}_{\mathrm{o}}=\left(\left(A e^{\lambda s}\right) R+A\right) e^{\lambda s}$

$\mathrm{B}_{0}=\left(\left(100 e^{6.504 \times 10^{-5} \cdot 3650}\right) 0.001+100\right) e^{6.504 \times 10^{-5.5} \cdot 3650}$

$\mathrm{B}_{0}=126.955 \mathrm{Ci}$

Should you wish to find the inventory amounts in grams (g) use the specific activity of the radionuclide in question.

Example 2a: $\quad$ SpA of Strontium $90 \quad=141(\mathrm{Ci} / \mathrm{g})$

$\begin{array}{ll}\text { Mass of Sr-90 in fuel pellet } & =\frac{126.955}{141} \\ \text { Mass of Sr-90 in fuel pellet } & =0.9 \mathrm{~g}\end{array}$


(This page intentionally left blank) 
(This page intentionally left blank) 